\title{
Dietary Karaya Saponin and Rhodobacter capsulatus Exert Hypocholesterolemic Effects by Suppression of Hepatic Cholesterol Synthesis and Promotion of Bile Acid Synthesis in Laying Hens
}

\author{
Sadia Afrose, Md. Sharoare Hossain, Ummay Salma, Abdul Gaffar Miah, and Hirotada Tsujii \\ Laboratory of Animal Biotechnology, Interdisciplinary Graduate School of Science and Technology, Shinshu University, \\ Minamiminowa-mura, Nagano 399-4598, Japan \\ Correspondence should be addressed to Hirotada Tsujii, htsujii@shinshu-u.ac.jp
}

Received 27 October 2009; Revised 18 February 2010; Accepted 17 May 2010

Academic Editor: Philippe G. Frank

Copyright ( $) 2010$ Sadia Afrose et al. This is an open access article distributed under the Creative Commons Attribution License, which permits unrestricted use, distribution, and reproduction in any medium, provided the original work is properly cited.

\begin{abstract}
This study was conducted to elucidate the mechanism underlying the hypolipidemic action of karaya saponin or Rhodobacter (R.) capsulatus. A total of 40 laying hens (20-week-old) were assigned into four dietary treatment groups and fed a basal diet (as a control) or basal diets supplemented with either karaya saponin, $R$. capsulatus, or both for 60 days. The level of serum low-density-lipoprotein cholesterol and the levels of cholesterol and triglycerides in the serum, liver, and egg yolk were reduced by all the supplementations $(P<.05)$. Liver bile acid concentration and fecal concentrations of cholesterol, triacylglycerol, and bile acid were simultaneously increased by the supplementation of karaya saponin, $R$. capsulatus, and the combination of karaya saponin and $R$. capsulatus $(P<.05)$. The supplementation of karaya saponin, $R$. capsulatus, and the combination of karaya saponin and $R$. capsulatus suppressed the incorporation of ${ }^{14} \mathrm{C}$ from $1-{ }^{14} \mathrm{C}$-palmitic acid into the fractions of total lipids, phospholipids, triacylglycerol, and cholesterol in the liver in vitro $(P<.05)$. These findings suggest that the hypocholesterolemic effects of karaya saponin and R. capsulatus are caused by the suppression of the cholesterol synthesis and the promotion of cholesterol catabolism in the liver.
\end{abstract}

\section{Introduction}

Saponins are natural detergent forms of a heterogeneous group of triterpene or steroid glycosides that occur in many hundreds of plant species [1]. A number of studies have shown that different kinds of saponins lower serum cholesterol levels in a variety of animals and human subjects [2-4]. Recently, we have reported that karaya saponin is the best hypocholesterolemic substrate, because karaya saponin reduced serum cholesterol concentration by $34 \%$ in rats while tea, quillaja, or soyabean saponins resulted in reductions of less than $20 \%$ [5]. We have also reported that Rhodobacter capsulatus (R. capsulatus), which is a photosynthetic bacterium, exhibits hypocholesterolemic activities in laying hens (15\%) [6], Japanese quails [7], rats [8], and pigs [9]. Furthermore, we found that the combination of karaya saponin and R. capsulatus as supplementation in a hen's diet causes much larger reductions in serum (32\%) and egg yolk cholesterol (18\%) levels than saponin alone [10]. However, the mechanism underlying the hypocholesterolemic effect of karaya saponin and R. capsulatus has not been clarified.

Recent studies have revealed that bile acids are ligands of several nuclear hormone receptors involved in regulating bile acid synthesis, transport, and cholesterol metabolism. The cholesterol pool is derived from two major sources: the synthesis of cholesterol by the liver and the absorption of cholesterol from the intestine [11]. The cholesterol pool rarely changes much because cholesterol input is approximately balanced by cholesterol output via factors such as excretion in bile/feces, skin excretion, and steroid hormone synthesis [12]. Suppression of cholesterol synthesis is also associated with hypocholesterolemia. Bile acid synthetic 
pathway is the major pathway of cholesterol catabolism. Zhao et al. [13] suggested that saponin lowers serum cholesterol by increasing the conversion of cholesterol into bile acids through the upregulation of a rate-limiting enzyme, CYP7A1, in hepatic bile acid synthesis. Therefore, it is possible that dietary karaya saponin and $R$. capsulatus exert hypocholesterolemic activity by the suppression of hepatic cholesterol synthesis and/or the promotion of bile acid synthesis in laying hens.

Thus, in the present study, we investigated the effect of karaya saponin and R. capsulatus on lipid metabolism in laying hens.

\section{Materials and Methods}

2.1. Birds, Management and Diets. A total of 40 Boris Brown ready-to-lay pullets with almost the same live weight were supplied by a local commercial flock and reared in individual cages $(30 \times 40 \mathrm{~cm})$. They were reared in accordance with the "Guidelines for Regulation of Animal Experimentation, Faculty of Agriculture, Shinshu University" and this study was approved by an ethics committee. The birds were fed a balanced commercial layer diet (Toyosashi Shiryo, Kabushiki Gaisha, Aichi, Japan) and reared as previously described in [6]. The basal diet contained (in percentages): ground yellow corn, 56; soybean meal, 14.5; sesame meal, 7; corn gluten meal, 2.5; rice polish, 8; fish meal, 1 ; calcium carbonate, 7.68; dicalcium phosphate, 1.32; common salt, 0.45 ; animal fat, 1 ; and vitamin premix, 0.25 . The calculated [14] nutrient composition of the basal diet was $2,935 \mathrm{kcal} / \mathrm{kg}$ of $\mathrm{ME}$, $16.46 \% \mathrm{CP}, 2.9 \% \mathrm{Ca}, 0.34 \%$ available P, $0.54 \%$ Met + Cys, $0.71 \%$ Lys, and $86 \mu \mathrm{g} / \mathrm{g}$ of cholesterol. There is no difference in fatty acid composition in experimental diets. Hens were assigned into four dietary treatment groups and fed the basal diet or basal diets supplemented with either $R$. capsulatus $(0.04 \%)$, karaya saponin $(75 \mathrm{mg} / \mathrm{kg}$ diet $)$, or both for a 60 day feeding period. Karaya saponin was obtained from Nacalai Tesque, Kyoto, Japan. R. capsulatus cells were grown in outdoor culture under natural illumination as previously described in [15]. The diets and water were provided ad libitum throughout the experiment, and a photoperiod of $16 \mathrm{~L}: 8 \mathrm{D}$ was used.

2.2. Sample Preparation and Enzymatic Analysis. The laying hens were weighed individually prior to blood collection at the beginning and at the end of each 2-week feeding period. Blood was collected from the brachial wing vein using sterilized syringes and needles. After $1 \mathrm{~h}$ standing at room temperature, serum was isolated by centrifugation at $1150 \times \mathrm{g}$ for $10 \mathrm{~min}$. Serum samples were stored at $-80^{\circ} \mathrm{C}$ until analysis. During the 60-day feeding period, feces were collected weekly from the control and treatment groups of laying hens. Cholesterol in the serum, egg yolk, liver, and feces were measured spectrophotometrically (APEL Co., Saitama, Japan) using a commercial kit (Wako Cholesterol E, Wako Pure Chemical Industries Ltd., Tokyo, Japan). Triacylglycerides were measured using a commercial kit (Wako TG, Wako Pure Chemical Industries Ltd., Tokyo,
Japan). High-density-lipoprotein (HDL) cholesterol in the serum was determined enzymatically using a commercial kit (Wako HDL-cholesterol, Wako Pure Chemical Industries Ltd.). Low-density-lipoprotein (LDL) cholesterol was determined using a commercial kit (Daiichi Pure Chemicals Co. Ltd, Tokyo, Japan) as described previously in [16]. For fecal and hepatic bile acid determination, feces and liver samples were ground and lyophilized, and $50 \mathrm{mg}$ of the lyophilized sample was placed in a centrifuge tube containing a $1 \mathrm{ml}$ mixture of $t$-butanol and water $(1: 1, \mathrm{v} / \mathrm{v})$ [17]. The tubes were vigorously vortexed, incubated for $20 \mathrm{~min}$ in a gently shaken water bath at $37^{\circ} \mathrm{C}$ and centrifuged at $1,000 \times \mathrm{g}$ for $2 \mathrm{~min}$. The supernatant was decanted into another tube and the bile acids were measured spectrophotometrically using a commercial kit (Wako TBA, Wako Pure Chemical Industries Ltd.).

2.3. Fatty Acid Determination. Total lipid extracts of yolk samples were transmethylated into fatty acid methyl esters and separated using a gas chromatograph (Shimadzu, GC14B, Kyoto, Japan) and an Omegawax 250 capillary column $(30 \mathrm{~m} \times 0.25 \mathrm{~mm}$ i.d.; $0.25 \mu \mathrm{m}$ thickness; Supelco, Bellefonte, PA, USA) with cyanopropyl methyl silicone as stationary phase. Helium was used as the carrier gas at a constant flow rate of $4.7 \mathrm{ml} / \mathrm{min}$. The following oven temperature program was used: $100^{\circ} \mathrm{C}$ held for $1 \mathrm{~min}$, increased to $160^{\circ} \mathrm{C}$ at $40^{\circ} \mathrm{C} / \mathrm{min}$ then to $240^{\circ} \mathrm{C}$ at $7^{\circ} \mathrm{C} / \mathrm{min}$, and $240^{\circ} \mathrm{C}$ held for $10 \mathrm{~min}$. Peaks were separated using a flame-ionization detector and quantified with an electric integrator (Shimadzu, CR-1A, Kyoto, Japan) using pure standard mixtures (Sigma, St. Louis, 151 MO, USA). We adopted the weight percentage of each fatty acid in all detected fatty acids as a measurement value.

2.4. Incorporation of $1{ }^{14} \mathrm{C}$-Palmitic Acid into Liver Tissue. At the end of the feeding period, the laying hens were decapitated, and left liver lobes were collected and chilled in icecold phosphate buffer solution (PBS). Liver lobes were sliced into $1 \mathrm{~mm}$ pieces, lightly pressed on sterilized paper and weighed prior to use in incubations with $1-{ }^{14} \mathrm{C}$-palmitate. About $0.5 \mathrm{~g}$ of liver slice was placed in the tube with $990 \mu \mathrm{l}$ of PBS and $37 \mathrm{KBq}(10 \mu \mathrm{l})$ of $1-{ }^{14} \mathrm{C}$-palmitic acid (specific activity: $1.92 \mathrm{GBq} / \mathrm{mmol}$; American Radiolabeled Chemicals Inc., St. Louis, MO, USA). The tubes were kept closed during the incubation period and agitated in a water-bath shaker at $39^{\circ} \mathrm{C}$ for 3 hours. At the end of the incubation, the tubes were placed in a freezer at $-40^{\circ} \mathrm{C}$ to stop the reaction. Tissue and medium were transferred to a cup containing five times their volume of chloroform-methanol $2: 1$ and homogenized. The homogenate was filtered through cotton filter paper. The residue was homogenized again with five times its volume of chloroform-methanol $2: 1$. This extraction step was repeated five times and the combined extracts were centrifuged at $1,150 \times \mathrm{g}$ for $10 \mathrm{~min}$. The chloroform layer was washed with saline solution three times in accordance with Folch et al. [18], which removed $99 \%$ of the water-soluble radioactive materials and then evaporated to dryness. Aliquots of hepatic lipids were separated by thin-layer chromatography (TLC) 
TABLE 1: Effect of dietary karaya saponin and R. capsulatus on LDL, HDL, total cholesterol, triacylglycerol, and bile acids in serum, liver, and feces of laying hens.

\begin{tabular}{|c|c|c|c|c|}
\hline \multirow{2}{*}{ Parameter } & \multicolumn{4}{|c|}{ Treatment } \\
\hline & Control & R. capsulatus & Saponin & Saponin + R. capsulatus \\
\hline \multicolumn{5}{|l|}{ Liver } \\
\hline Cholesterol (mM/g) & $1.10 \pm 0.12^{\mathrm{a}}$ & $0.59 \pm 0.09^{\mathrm{b}}$ & $0.61 \pm 0.08^{\mathrm{b}}$ & $0.47 \pm 0.04^{\mathrm{b}}$ \\
\hline Triacylglycerol (mM/g) & $1.65 \pm 0.15^{\mathrm{a}}$ & $1.12 \pm 0.10^{\mathrm{b}}$ & $1.03 \pm 0.04^{\mathrm{b}}$ & $0.98 \pm 0.03^{\mathrm{b}}$ \\
\hline Bile acids (nM/g) & $51.9 \pm 3.25^{\mathrm{a}}$ & $68.6 \pm 3.16^{\mathrm{b}}$ & $70.15 \pm 4.22^{\mathrm{b}}$ & $74.4 \pm 3.35^{\mathrm{b}}$ \\
\hline \multicolumn{5}{|l|}{ Fecal } \\
\hline Cholesterol (mM/g) & $0.71 \pm 0.05^{\mathrm{a}}$ & $0.96 \pm 0.11^{\mathrm{b}}$ & $0.98 \pm 0.23^{\mathrm{b}}$ & $1.20 \pm 0.16^{\mathrm{b}}$ \\
\hline Triacylglycerol (mM/g) & $0.80 \pm 0.17^{\mathrm{a}}$ & $1.20 \pm 0.21^{\mathrm{b}}$ & $1.26 \pm 0.14^{\mathrm{b}}$ & $1.21 \pm 0.12^{\mathrm{b}}$ \\
\hline Bile acids (nM/g) & $98.0 \pm 5.35^{\mathrm{a}}$ & $136.6 \pm 6.23^{\mathrm{b}}$ & $143.52 \pm 5.54^{\mathrm{b}}$ & $158.04 \pm 7.15^{\mathrm{c}}$ \\
\hline \multicolumn{5}{|l|}{ Serum } \\
\hline Cholesterol (mM/L) & $3.91 \pm 1.18^{\mathrm{a}}$ & $3.38 \pm 0.42^{b}$ & $3.16 \pm 0.32^{b}$ & $3.07 \pm 0.45^{\mathrm{b}}$ \\
\hline Triacylglycerol (mM/L) & $4.58 \pm 0.95^{\mathrm{a}}$ & $4.26 \pm 1.03^{\mathrm{b}}$ & $4.29 \pm 1.21^{\mathrm{b}}$ & $4.05 \pm 1.63^{\mathrm{b}}$ \\
\hline LDL-cholesterol (mg/dL) & $112.53 \pm 3.44^{\mathrm{a}}$ & $96.24 \pm 3.26^{\mathrm{ab}}$ & $91.67 \pm 4.25^{\mathrm{b}}$ & $80.16 \pm 3.45^{c}$ \\
\hline HDL-cholesterol (mg/dL) & $46.25 \pm 2.36^{\mathrm{a}}$ & $44.31 \pm 4.13^{\mathrm{ab}}$ & $50.33 \pm 5.24^{\mathrm{b}}$ & $58.81 \pm 4.37^{\mathrm{b}}$ \\
\hline \multicolumn{5}{|l|}{ Yolk } \\
\hline Cholesterol (mM/g) & $3.65 \pm 0.89^{\mathrm{a}}$ & $3.40 \pm 0.74^{\mathrm{b}}$ & $3.38 \pm 0.55^{\mathrm{b}}$ & $3.19 \pm 0.62^{b}$ \\
\hline Triacylglycerol (mM/g) & $23.6 \pm 2.16^{\mathrm{a}}$ & $20.7 \pm 2.04^{\mathrm{b}}$ & $21.71 \pm 3.25^{\mathrm{b}}$ & $19.86 \pm 2.66^{\mathrm{b}}$ \\
\hline
\end{tabular}

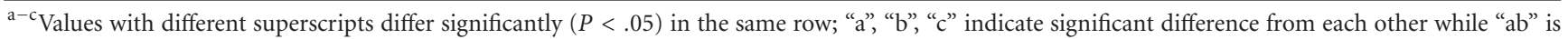
not significant. Values are mean \pm SD for 10 laying hens per group. Differences were tested by Duncan multiple range test. HDL $=H i g h$ density lipoprotein; $\mathrm{LDL}=$ Low density lipoprotein.

using Silica Gel G as the adsorbent and hexane-diethyl ether-formic acid (80-20-1) as the solvent. The fractions were detected under ultraviolet light $(320 \mathrm{~nm})$ after spraying the TLC plates with a methanolic solution $(0.2 \%)$ of $2^{\prime} 7^{\prime}$ dichlorofluorescein, and the spots were detected using the standards for phospholipids, cholesterol, triacylglycerol, and cholesterol esters. Spots were scraped from the plates and collected separately in scintillation vials containing $5 \mathrm{ml}$ of scintillation cocktail. The radioactivity of the samples was then measured using a liquid scintillation counter (LS-6500; Beckman Instruments, Fullerton, CA, USA).

2.5. Statistical Analyses. All data were analyzed by analysis of variance using the GLM procedure of SAS (SAS Institute, Cary, NC). Individual treatment differences were tested by Duncan multiple-range test. Data were presented as means \pm SDs. Differences were considered significant at the level of $P<.05$.

\section{Results}

As shown in Table 1, dietary karaya saponin, $R$. capsulatus and their combination significantly reduced $(P<.05)$ the hepatic total cholesterol and triacylglyceride levels whereas they increase bile acid concentration $(P<.05)$. On the other hand, the fecal excretions of cholesterol and triacylglycerides were significantly increased by karaya saponin, $R$. capsulatus and their combination. The excretion of fecal bile acid was significantly higher for all the treatments $(P<.05)$. The concentrations of total cholesterol and triacylglycerol in the serum and egg yolk were significantly decreased $(P<.05)$ by karaya saponin, $R$. capsulatus and their combination. Serum cholesterol concentration was significantly decreased $(P<.05)$ and serum HDL-cholesterol concentration was significantly increased $(P<.05)$ in the karaya saponin and karaya saponin $+R$. capsulatus groups compared with those in control group.

The effects of dietary karaya saponin and $R$. capsulatus on fatty acid composition in the egg yolk of laying hens are shown in Table 2. The concentrations of oleic, linoleic and linolenic acids in the egg yolk were significantly $(P<.05)$ increased by the karaya saponin, $R$. capsulatus and karaya saponin $+R$. capsulatus supplemented diets as compared with those with the control diet. Consequently, concentrations of polyunsaturated fatty acids (PUFA) were significantly $(P<.05)$ increased in the egg yolk of karaya saponin, $R$. capsulatus and karaya saponin $+R$. capsulatus supplemented groups compared with those of the control group. The ratio of PUFA to saturated fatty acids (SFA), and PUFA and monounsaturated fatty acids (MUFA) to SFA, in the egg yolk of the karaya saponin and karaya saponin $+R$. capsulatus groups were significantly higher $(P<.05)$ than those in the control group.

The effects of dietary karaya saponin and $R$. capsulatus on the incorporation of $1-{ }^{14} \mathrm{C}$-palmitic acid into hepatic lipids of laying hens are shown in Figure 1. There was a significantly lower $(P<.05)$ incorporation of ${ }^{14} \mathrm{C}$ into hepatic total lipids, triacylglycerides, and total cholesterol of hens in the karaya saponin, $R$. capsulatus and karaya 
TABLE 2: Effect of dietary karaya saponin and R. capsulatus on yolk fatty acids.

\begin{tabular}{|c|c|c|c|c|}
\hline \multirow{2}{*}{ Fatty acid } & \multicolumn{4}{|c|}{ Treatment } \\
\hline & Control & R. capsulatus & Saponin & Saponin + R. capsulatus \\
\hline $16: 0$ & $5.90 \pm 0.48^{\mathrm{a}}$ & $6.78 \pm 0.99^{\mathrm{ab}}$ & $5.83 \pm 0.52^{\mathrm{ab}}$ & $4.08 \pm 0.65^{\mathrm{b}}$ \\
\hline $18: 0$ & $2.01 \pm 0.19$ & $2.81 \pm 0.28$ & $1.93 \pm 0.17$ & $1.85 \pm 0.15$ \\
\hline $16: 1$ & $0.71 \pm 0.07$ & $1.08 \pm 0.16$ & $1.13 \pm 0.20$ & $1.11 \pm 0.09$ \\
\hline $18: 1$ & $7.46 \pm 0.88^{\mathrm{a}}$ & $12.36 \pm 1.14^{\mathrm{b}}$ & $10.75 \pm 1.84^{\mathrm{b}}$ & $14.10 \pm 1.65^{\mathrm{c}}$ \\
\hline $18: 2$ & $11.87 \pm 0.97^{\mathrm{a}}$ & $16.34 \pm 1.97^{\mathrm{b}}$ & $18.25 \pm 2.01^{\mathrm{b}}$ & $17.44 \pm 1.88^{\mathrm{b}}$ \\
\hline $18: 3$ & $2.67 \pm 0.17^{\mathrm{a}}$ & $4.16 \pm 0.53^{\mathrm{b}}$ & $4.33 \pm 0.62^{\mathrm{b}}$ & $5.01 \pm 0.41^{\mathrm{b}}$ \\
\hline MUFA & $8.10 \pm 0.47^{\mathrm{a}}$ & $12.89 \pm 1.16^{\mathrm{b}}$ & $11.75 \pm 1.13^{\mathrm{ab}}$ & $14.78 \pm 1.23^{\mathrm{c}}$ \\
\hline PUFA & $14.47 \pm 1.05^{\mathrm{a}}$ & $20.50 \pm 0.86^{\mathrm{b}}$ & $22.16 \pm 1.57^{\mathrm{b}}$ & $22.08 \pm 2.11^{\mathrm{b}}$ \\
\hline SFA & $7.89 \pm 0.82$ & $9.59 \pm 0.54$ & $7.48 \pm 0.43$ & $5.77 \pm 0.22$ \\
\hline PUFA : SFA & $1.81 \pm 0.09^{\mathrm{a}}$ & $2.14 \pm 0.08^{\mathrm{ab}}$ & $2.91 \pm 0.05^{\mathrm{b}}$ & $3.80 \pm 0.25^{\mathrm{b}}$ \\
\hline (PUFA+MUFA) : SFA & $2.82 \pm 0.11^{\mathrm{a}}$ & $3.25 \pm 0.24^{\mathrm{ab}}$ & $4.50 \pm 0.31^{\mathrm{b}}$ & $6.12 \pm 0.35^{\mathrm{b}}$ \\
\hline
\end{tabular}

${ }^{a-c}$ Values with different superscripts differ significantly $(P<.05)$ in the same row; "a", "b", "c" indicate significant difference from each other while "ab" is not significant. Values are means $\pm \mathrm{SD}(\mathrm{mg} / \mathrm{g})$ for 10 laying hens per group.

Differences were tested by Duncan multiple range test. MUFA= monounsaturated fatty acids, PUSA= polyunsaturated fatty acids, SFA= saturated fatty acids.

saponin $+R$. capsulatus supplemented groups than that in the control group. There was no significant difference in the incorporation of ${ }^{14} \mathrm{C}$ from palmitic acid into the cholesterol ester fraction between groups. In the phospholipid fraction, all the treatments significantly reduced incorporation, and the trends of $R$. capsulatus and saponin $+R$. capsulatus treatments were similar.

\section{Discussion}

The present study expands our understanding of the cholesterol-lowering effects of karaya saponin and R. capsulatus in laying hens. In this study, we found that the fecal excretion of bile acids in the laying hens was significantly increased by karaya saponin, $R$. capsulatus or karaya saponin $+R$. capsulatus supplemented diet compared with that with the control diet. Similarly, liver bile acid was also increased by all the treatments. In both feces and liver, the trends for bile acid were similar and the highest bile acid concentration was found when karaya saponin and $R$. capsulatus, were used in combination. This indicates that these two natural ingredients can function synergistically, at least in laying hens. These results are in agreement with our previous observations described in Afrose et al. [10] and Salma et al. [6]. Many pathways and factors have been reported to contribute to the hypocholesterolemic effects of different dietary saponins. Cholesterol reduction by karaya saponin and $R$. capsulatus is a new approach that continues to stimulate much research and discussion. Plant saponins exhibit many of the characteristics desirable for long-term hyperlipidemic therapy and thus may represent a novel form of therapy for the treatment of hypercholesterolemia [19]. In spite of the fact that a great variety of investigations on the biological activities of saponins have been carried out [20], studies on their effects on bile acid, as described here, are rare, aside from a number with steroid saponins.
In this study, the consequent increase in fecal excretion is compensated for by enhanced hepatic conversion of cholesterol to bile acid. Support of this finding comes from an observation by Oakenfull and Fenwick [21] that plant fiber preparations containing saponins bind to bile acids in vitro. Oakenfull et al. [22] further concluded that $1 \%$ soyasaponins significantly increase fecal bile acid and neutral sterol excretion compared with a control diet without soyasaponin. From this study, it was also observed that cholesterol reduction and fecal cholesterol excretion are inversely correlated with similar magnitudes. Thus, it is conceivable from this study that the cholesterol-lowering effect of saponin might be due to the increase in bile acid excretion [23] that occurs through interference with the absorption of cholesterol [24]. Potter [25] also indicated that saponin might alter the absorption of cholesterol and bile acid. One of the possible mechanisms for this effect is that saponin forms micelles with bile acid [26]. It has been postulated that a saponin from platycodins may interrupt the formation of cholesterol micelles by cocrystallizing with cholesterol [27]. Lin et al. [28] also pointed out that saponin binds a certain amount of bile acid when added to a diet in rats.

The resulting decrease in cholesterol synthesis, which was observed in laying hens that were administered feed with karaya saponin and $R$. capsulatus, leads to hypocholesterolemia. The determination of the incorporation of labeled palmitic acid into total lipids and the various lipid fractions provides an indication of the pattern of lipid synthesis influenced by the combination of karaya saponin and R. capsulatus supplementation. However, our study indicates that the classes of liver lipid were not all affected by saponin or R. capsulatus in the same manner and magnitude. Decreased hepatic synthesis of cholesterol from precursor palmitic acid from the saponin or R. capsulatus supplemented diet is the most detectable hypocholesterolemic effect. Although the suppression of individual cholesterol synthesis was similar 


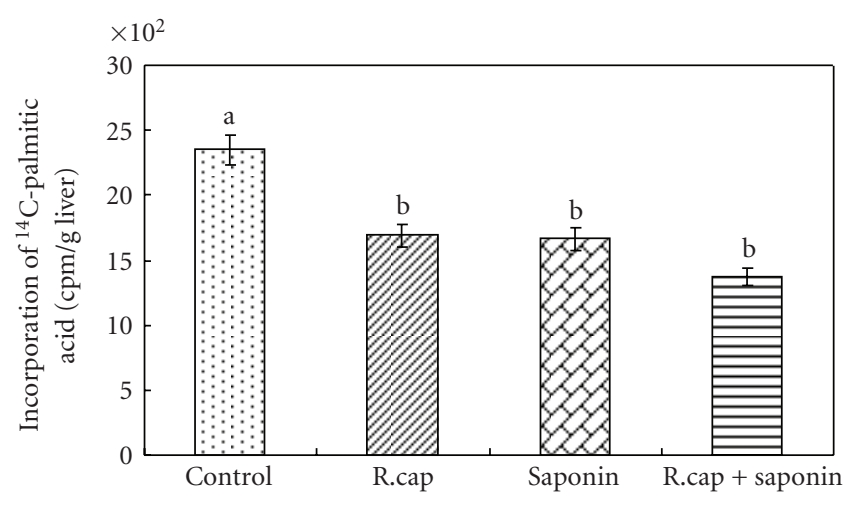

(a) Total lipids

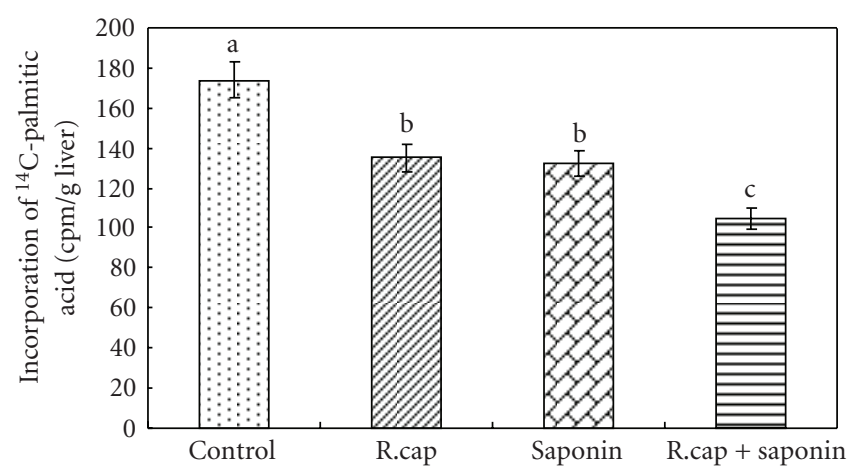

(c) Cholesterol

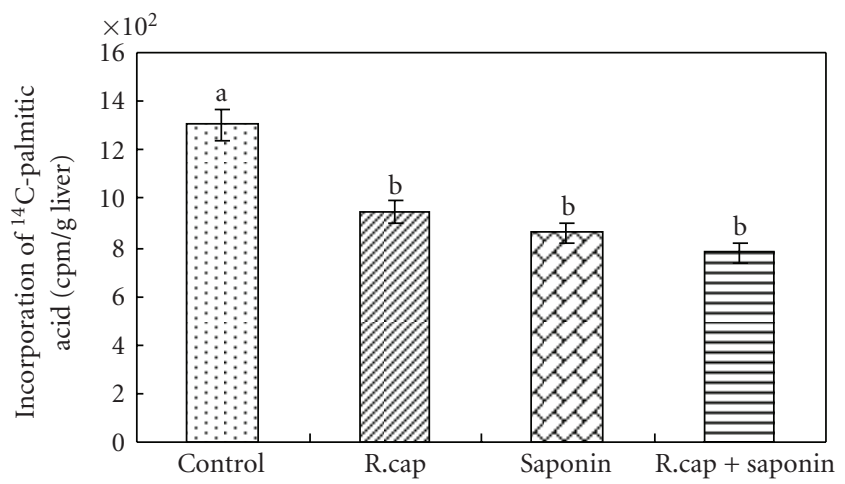

(b) Triacylglycerol

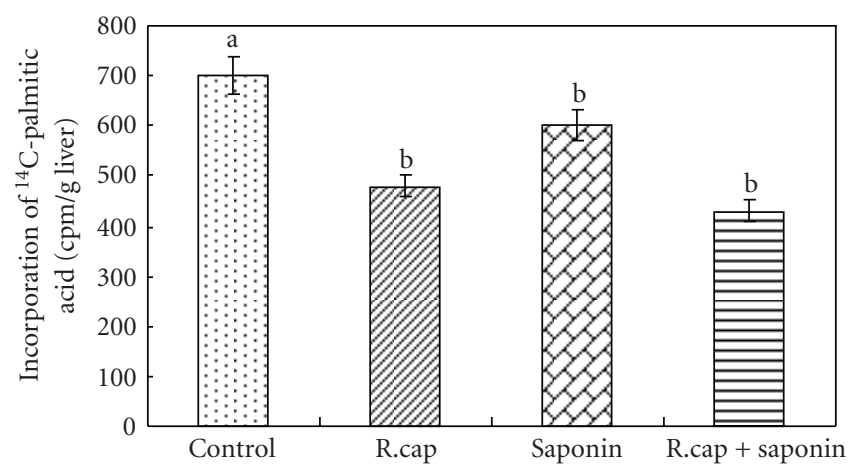

(d) Phospholipids

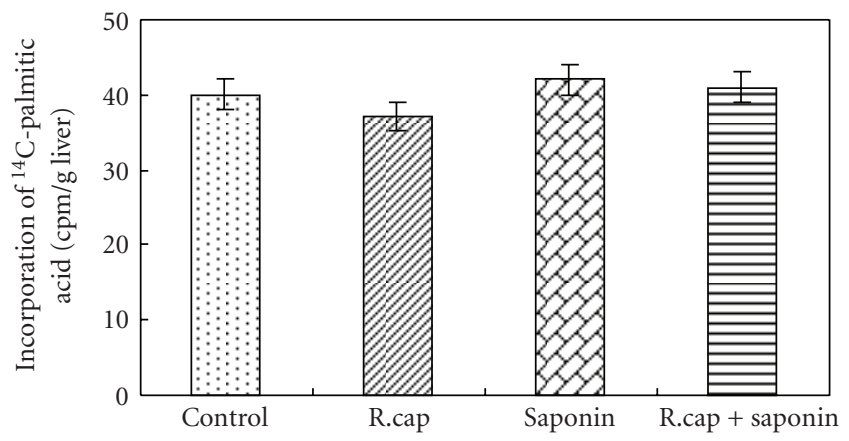

(e) Cholesterol ester

FIGURE 1: Effect of dietary karaya saponin and R. capsulatus on the incorporation of $1-{ }^{14} \mathrm{C}$-palmitic acid into hepatic (a) total lipids, (b) triacylglycerol, (c) cholesterol, (d) phospholipids, and (e) cholesterol ester fraction. Differences were tested by Duncan multiple-range test. ${ }^{a-c}$ Values with different superscripts differ significantly $(P<.05)$; "a", "b", "c" indicate significant difference from each other. Values are mean $\pm \mathrm{SD}, n=10$ laying hens.

for individual saponin or $R$. capsulatus, the combination of these two caused a marked decrease. Thus, the synergistic effect of karaya saponin and R. capsulatus on the suppression of cholesterogenesis is in agreement with the low hepatic cholesterol concentration (as shown in Table 1). It was suggested that by virtue of their purported intestinal action, saponins could provide a nonsystemic alternative to the commonly used HMG-CoA reductase inhibitors [29]. It is possible that karaya saponin together with $R$. capsulatus suppresses cholesterol synthesis by reducing HMG-CoA activity. When palmitic acid is used as a substrate for lipid synthesis under in vitro conditions, dietary saponin and $R$. capsulatus could tend to reduce palmitic acid incorporation into some lipid classes by causing a reduction in malonylCoA formation. This suppression of cholesterol synthesis is in line with our previous observations in chickens $[6,10]$. The pattern of palmitic acid distribution in the various lipid fractions of liver was different between the treatment group and the control. Synthesis of triacylglycerol predominates in the chicken liver, while karaya saponin and R. capsulatus markedly reduced this synthesis. When karaya saponin with $R$. capsulatus was fed to hens, there was an approximately 
$25 \%$ reduction in cholesterol synthesis. Thus, the suppressed esterification of $1-{ }^{14} \mathrm{C}$-palmitic acid into triacylglycerol and cholesterol is one of the potential hypocholesterolemic mechanisms of karaya saponin and $R$. capsulatus in laying hens.

Simultaneously, the excretion of cholesterol through feces was also enhanced by the combined supplementation of karaya saponin and $R$. capsulatus. The evidence from this study suggests that this aspect of cholesterol trafficking is not the cause of cholesterol modulation. Using a single cholesterol tracer method, previously validated against the dual isotope ratio methodology, Southon et al. [2] have shown that cholesterol absorption increased in the animals receiving a high dose of saponin. Cholesterol excretion and hepato-biliary-intestinal efflux of cholesterol appear to be the mechanisms responsible for the lower circulating levels. However, our data suggest that karaya saponin acting synergistically with $R$. capsulatus likely increased fecal cholesterol excretion as fecal cholesterol concentration was increased 2 -fold. In a recent study, it was observed that saponin enhanced intestinal sterol permeability, resulting in increased cholesterol absorption; on the other hand, there are still certain unknown mechanisms that exist that can enhance cholesterol efflux, resulting in a net depletion of the sterol pool [13]. It is conceivable from our study that hepatic increased bile acid resulted in fecal cholesterol excretion. The concentration of excreted cholesterol was 35\% higher in the laying hens fed both the karaya saponin and $R$. capsulatus supplemented diet than in those fed the control diet.

In this study, some fatty acids in egg yolk were altered by the karaya saponin and $R$. capsulatus supplementation. We previously reported that dietary supplementation of $R$. capsulatus altered the fatty acid composition of serum lipid in rats [5]. In the present study, the combination of dietary saponin and $R$. capsulatus resulted in a significant increase in the oleic, linoleic, and linolenic acid concentrations in egg yolk. In broiler chickens, Salma et al. [7] reported that the concentrations of oleic, linoleic, and linolenic acids in breast and thigh meat are markedly increased by the combined supplementation in chickens. Our findings clearly demonstrate that dietary R. capsulatus can improve the fatty acid composition in eggs. Although the levels of saturated palmitic and stearic acids were slightly increased by the $R$. capsulatus supplementation, they were markedly decreased when the combination of saponin and $R$. capsulatus was introduced to the diet. The alteration of the egg yolk fatty acid profile by saponin and $R$. capsulatus supplementation might provide health benefits. Despite the fatty acid alteration effects, nothing is known about the mode of action and mechanism by which karaya saponin enhances PUFA. Thus, it will be interesting to elucidate the mechanism underlying this phenomenon.

Although it is difficult to completely characterize the mechanism of the action of karaya saponin, counteraction of bile activity might explain the reduced cholesterol bioaccessibility observed when karaya saponin is introduced into the diet. The mechanism of karaya saponin and $R$. capsulatus hypolipidemic action might also involve the posttranscriptional suppression of HMG-CoA reductase in a manner mimicking the action of putative nonsterol feedback inhibitors. Further studies are needed to confirm these effects. In conclusion, karaya saponin and R. capsulatus supplementation feeding resulted in a pronounced cholesterollowering effect. Our study suggests that the reductions in the levels of serum and egg cholesterol are caused by the suppression of cholesterol synthesis and the promotion of cholesterol catabolism in the liver.

\section{References}

[1] G. S. Sidhu and D. G. Oakenfull, "A mechanism for the hypocholesterolaemic activity of saponins," British Journal of Nutrition, vol. 55, no. 3, pp. 643-649, 1986.

[2] S. Southon, A. J. A. Wright, K. R. Price, S. J. Fairweather-Tait, and G. R. Fenwick, "The effect of three types of saponin on iron and zinc absorption from a single meal in the rat," British Journal of Nutrition, vol. 59, no. 3, pp. 389-396, 1988.

[3] S. M. Potter, R. Jimenez-Flores, J. Pollack, T. A. Lone, and M. D. Berber-Jimenez, "Protein-saponin interaction and its influence on blood lipids," Journal of Agricultural and Food Chemistry, vol. 41, no. 8, pp. 1287-1291, 1993.

[4] H. Matsuura, "Saponins in garlic as modifiers of the risk of cardiovascular disease," Journal of Nutrition, vol. 131, no. 3, pp. 1000S-1005S, 2001.

[5] S. Afrose, MD. S. Hossain, T. Maki, and H. Tsujii, "Karaya root saponin exerts a hypocholesterolemic response in rats fed a high-cholesterol diet," Nutrition Research, vol. 29, no. 5, pp. 350-354, 2009.

[6] U. Salma, A. G. Miah, K. M. A. Tareq, T. Maki, and H. Tsujii, "Effect of dietary Rhodobacter capsulatus on egg-yolk cholesterol and laying hen performance," Poultry Science, vol. 86, no. 4, pp. 714-719, 2007.

[7] U. Salma, A. G. Miah, T. Maki, and H. Tsujii, "Effect of dietary Rhodobacter capsulatus on cholesterol concentration and fatty acid composition in Japanese quail," Journal of Poultry Science, vol. 44, no. 4, pp. 375-382, 2007.

[8] H. Tsujii, M. Nishioka, U. Salma, A. G. Miah, T. Maki, and M. G. Lee, "Comparative study on hypocholesterolemic effect of Rhodopseudomonas palustris and Rhodobacter capsulatus on rats fed a high cholesterol diet," Animal Science Journal, vol. 78, no. 5, pp. 535-540, 2007.

[9] H. Tsujii, Y. Kuwabara, U. Salma, A. G. Miah, M. Nishimura, and T. Maki, "Effect of dietary Rhodobacter capsulatus on cholesterol, triglycerides concentration, and meat quality of finishing pigs," Animal Science Journal, vol. 79, no. 4, pp. 460465, 2008.

[10] S. Afrose, M. S. Hossain, T. Maki, and H. Tsujii, "Effect of dietary karaya saponin on serum and egg yolk cholesterol in laying hens," British Poulry Science. In press.

[11] E. Levy, S. Spahis, D. Sinnett et al., "Intestinal cholesterol transport proteins: an update and beyond," Current Opinion in Lipidology, vol. 18, no. 3, pp. 310-318, 2007.

[12] D. R. Illingworth, P. B. Duell, and W. E. Connor, "Disorders of lipid metabolism," in Endocrinology and Metabolism, P. Felig, J. D. Baxter, and L. A. Frohman, Eds., pp. 1315-1403, McGrawHill, New York, NY, USA, 1995.

[13] H. L. Zhao, S. V. Harding, C. P.F. Marinangeli, Y. S. Kim, and P. J.H. Jones, "Hypocholesterolemic and anti-obesity effects of saponins from Platycodon grandiflorum in hamsters fed atherogenic diets," Journal of Food Science, vol. 73, no. 8, pp. 195-200, 2008. 
[14] AOAC, Official Methods of Analysis. Association of Official Analytical Chemists, 1995.

[15] M. Kobayashi and S. Kurata, "The mass culture and cell utilization of photosynthetic bacteria," Process Biochemistry, vol. 13, pp. 27-29, 1978.

[16] N. Shapira and J. Pinchasov, "Modified egg composition to reduce low-density lipoprotein oxidizability: high monounsaturated fatty acids and antioxidants versus regular high $n$ 6 polyunsaturated fatty acids," in Journal of Agricultural and Food Chemistry, vol. 56, no. 10, pp. 3688-3693, May 2008.

[17] R. Van der Meer, H. de Vries, and J. F. C. Glatz, Studies in the Netherlands, Ponsen \& Looijen, Netherlands, 1985.

[18] J. Folch, M. Lees, and G. H. Stanley, "A simple method for the isolation and purification of total lipides from animal tissues," The Journal of Biological Chemistry, vol. 226, no. 1, pp. 497$509,1957$.

[19] H. J. Harwood, C. E. Chandler, and L. D. Pellarin, "Pharmacologic consequences of cholesterol absorption inhibition: alteration in cholesterol metabolism and reduction in plasma cholesterol concentration induced by the synthetic saponin beta-tigogenin cellobioside (CP-88818; tiqueside)," Journal of Lipid Research, vol. 34, pp. 377-395, 1993.

[20] S. B. Mahato, S. K. Sarkar, and G. Poddar, "Triterpenoid saponins," Phytochemistry, vol. 27, pp. 3037-3067, 1988.

[21] D. G. Oakenfull and D. E. Fenwick, "Adsorption of bile salts from aqueous solution by plant fibre and cholestyramine," British Journal of Nutrition, vol. 40, no. 2, pp. 299-309, 1978.

[22] D. G. Oakenfull, D. L. Topping, R. J. Illman, and D. E. Fenwick, "Prevention of dietary hypercholesterolaemia in the rat by soya bean and quillaja saponins," Nutrition Reports International, vol. 29, no. 5, pp. 1039-1046, 1984.

[23] J. W. Erdman Jr., "Soy protein and cardiovascular disease: a statement for healthcare professionals from the nutrition committee of the AHA," Circulation, vol. 102, no. 20, pp. 2555-2559, 2000.

[24] D. H. Shin, H. J. Heo, Y. J. Lee, and H. K. Kim, "Amaranth squalene is reduced serum and liver lipid levels in been fed a cholesterol diet," British Journal of Biomedical Science, vol. 61, pp. 11-14, 2004.

[25] S. M. Potter, "Overview of proposed mechanisms for the hypocholesterolemic effect of soy," Journal of Nutrition, vol. 125, supplement 3, pp. 606S-611S, 1995.

[26] D. Oakenfull and B. H. Arjmandi, "Soy protein, saponins and plasma cholesterol," Journal of Nutrition, vol. 131, no. 11, pp. 2971-2972, 2001.

[27] H. L. Zhao, S. V. Harding, C. P. F. Marinangeli, Y. S. Kim, and P. J.H. Jones, "Hypocholesterolemic and anti-obesity effects of saponins from Platycodon grandiflorum in hamsters fed atherogenic diets," Journal of Food Science, vol. 73, no. 8, pp. H195-H200, 2008.

[28] C.-Y. Lin, C.-Y. Tsai, and S.-H. Lin, "Effects of soy components on blood and liver lipids in rats fed high-cholesterol diets," World Journal of Gastroenterology, vol. 11, no. 35, pp. 55495552, 2005.

[29] L. A. Morehouse, F. W. Bangerter, and M. P. DeNinno, "Comparison of synthetic saponin cholesterol absorption inhibitors in rabbits: evidence for a Non-Stoichiometric, intestinal mechanism of action," Journal of Lipid Research, vol. 40, pp. 464-474, 1999. 


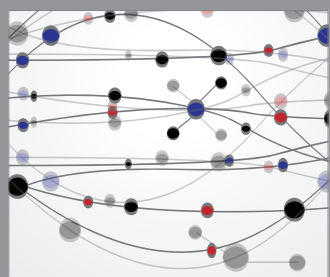

The Scientific World Journal
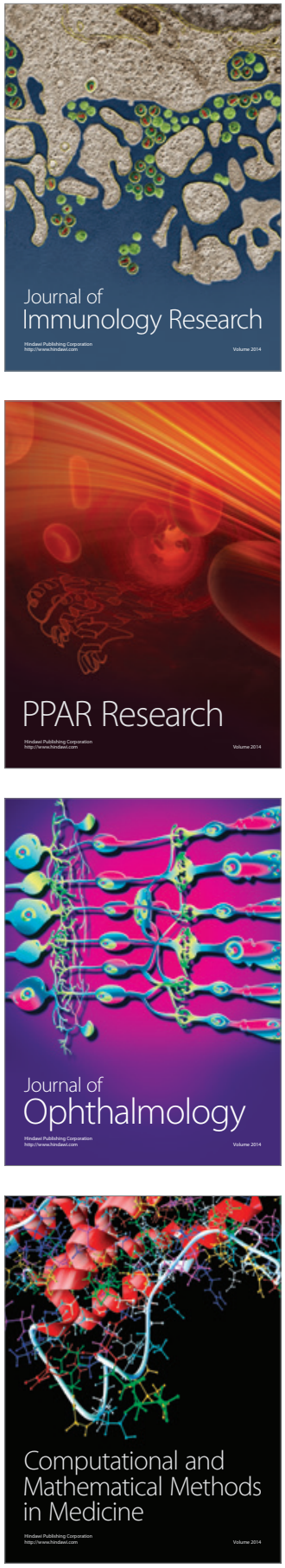

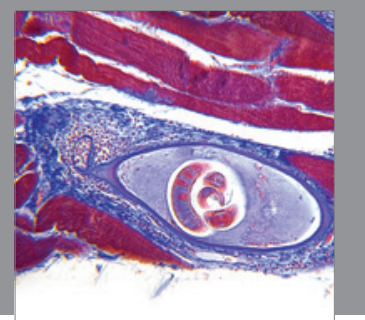

Gastroenterology

Research and Practice
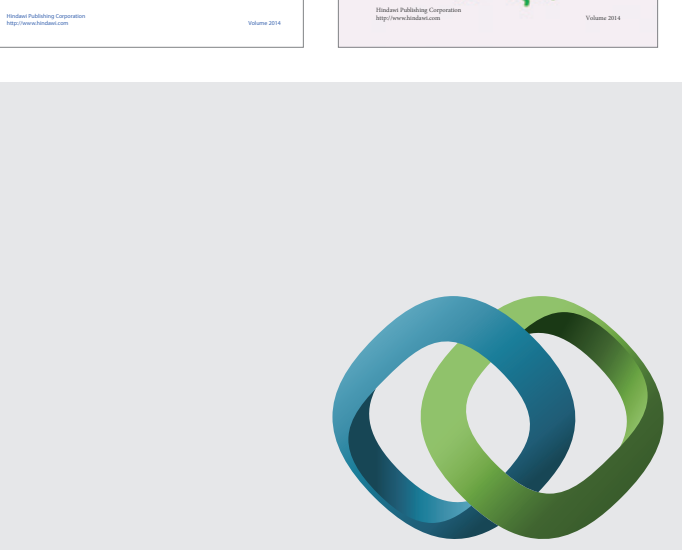

\section{Hindawi}

Submit your manuscripts at

http://www.hindawi.com
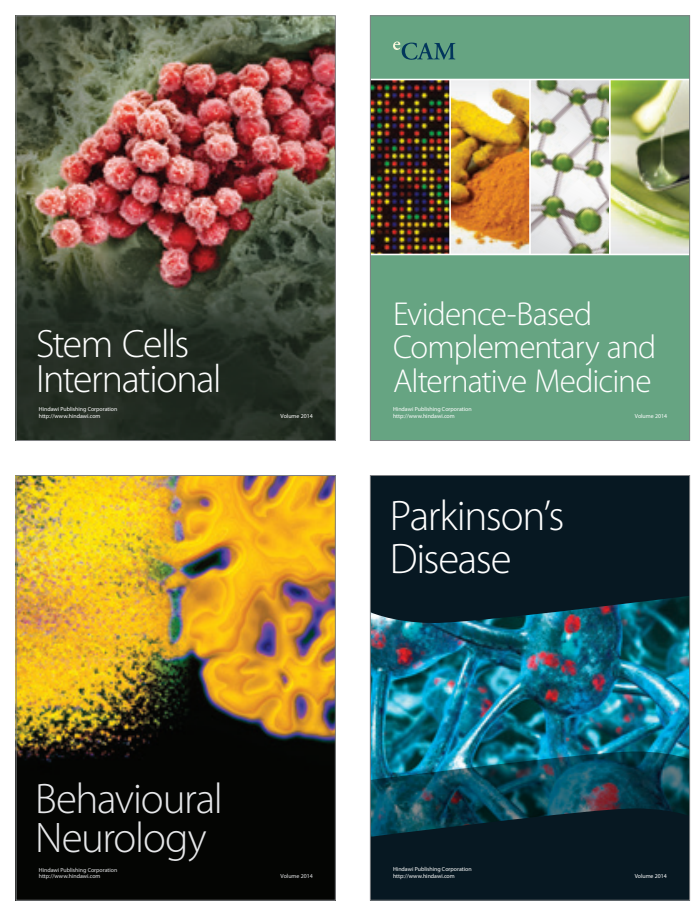

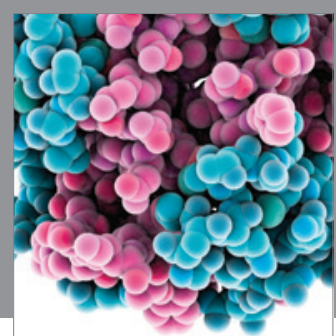

Journal of
Diabetes Research

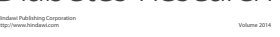

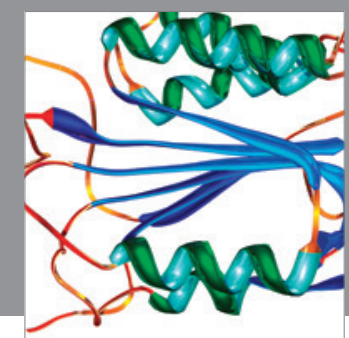

Disease Markers
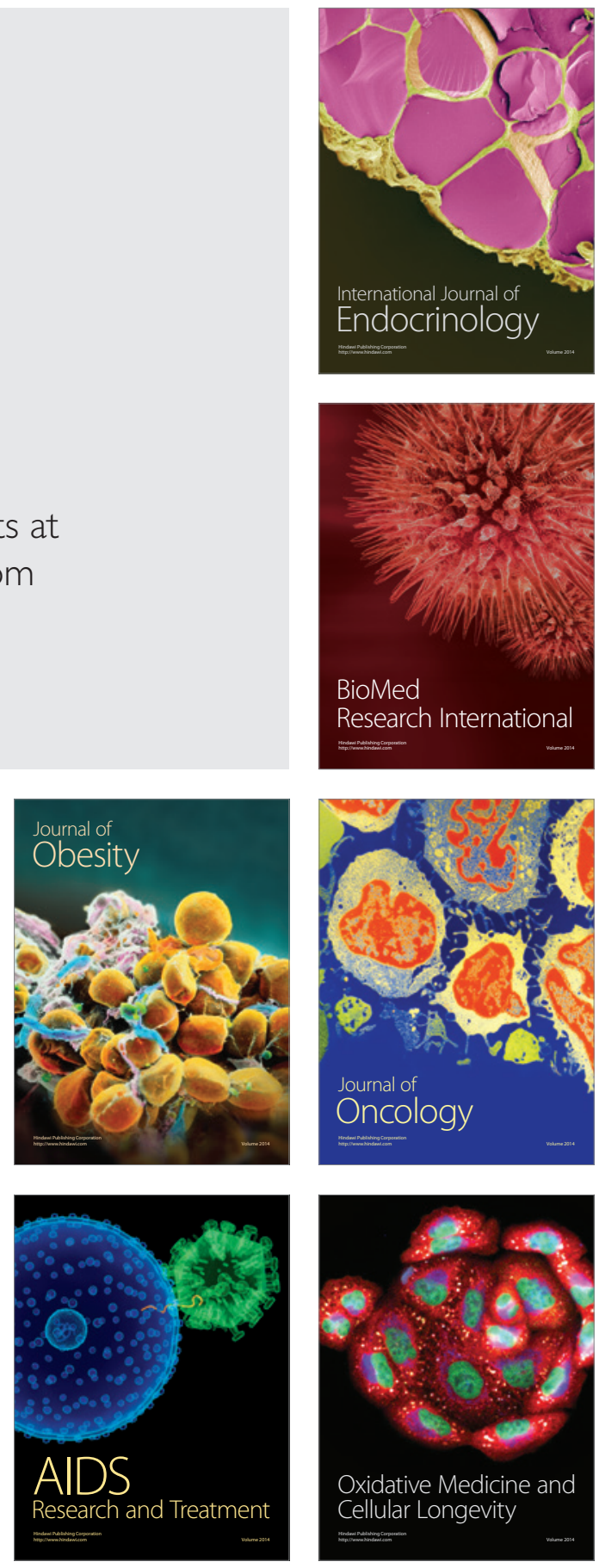